\title{
Convocation Address - IV
}

\section{H D S De Alwis}

(Eminent Engineer -Convocation Address on 18 November 2009)

It is indeed a privilege for me to be granted this opportunity to address this august gathering, at this prestigious Convocation ceremony today, and share a few thoughts focused on the issues related to 'Engineering Education, vis-a-vis the Engineering Industry.

This topic undoubtedly has not only gained much publicity but has also demanded the complete and unwavering attention of each and every well-minded member of a just and equitable society, more specifically with regard to our 'Education Systems and Curricula' and the Broad-Based Reforms required therein, in a contemporary context.

It is needles to say that our 'Engineering Education' needs immediate reform and expansion, to suit and match the nation's Engineering Industry. The Engineering Education mechanism should be developed with an innovative package of policies initiated by the Ministry of Higher Education, to contribute to the process of economic development in the country.

Sri Lanka needs people capable of working in its fast expanding service industry and in running manufacturing businesses. There is also a need for talented and energetic youth to engage themselves in agriculture water-related infrastructure etc.

Memorising facts and figures in the classroom is becoming increasingly redundant, as much information needed is readily and easily available on the internet and by other means. Therefore our secondary educational institutions or schools, should place less emphasis on 'Rote Learning' and the 'Testing of Knowledge only via Exams'. There should be greater focus on skills such as 'Analysis of Information', Thinking, Reasoning, Debating, and Philosophy instead.

We need to re-structure our school curricular by balancing the acquisition of knowledge with more valuable skills of analysis, critical thinking, synthesis of ideas and abstract reasoning. 
The G.C.E. (Advanced Level) mechanism needs considerable attention of the policy makers and the so-called intellectual Gurus. At present it lacks both a Practical Test and a 'Viva-Voce' which were once the hallmarks for selection in to the universities, in the by-gone era. The four subjects which one had to sit for, to qualify for the universities then, had been pruned down to three. These aspects too should be open for debate and amended accordingly, for the better.

Sri Lanka is one such country in this part of the world, which has a comparatively stable and developed human resource base which came into existence on the basis of the social demand module of education. It is this model which guaranteed equality of opportunity in education, and education was freely available from kindergarten to the university.

Under this mechanism, educational opportunities were expanded and a network of secondary schools operated to produce thousands of qualified men and women requiring tertiary educational institutions or the universities.

Albeit the universities expanded in numbers, in response to the impact of the social demand model of education, they failed to provide all the aspirants this facility. Annually, universities could only provide to around 21,000 students from a comparatively larger number of around 100,000 qualified for the same. This per se, is a challenge and causes a major imbalance in the whole system of higher education.

Furthermore, the quality of undergraduate education had deteriorated within the last several decades, purely due to the absence of a learning culture in the universities, where the intellectual competencies have been stifled by groups of agitation-oriented and politically motivated students linked to political parties.

In a bid to enhance the quality of the engineering profession, the reestablishment of a period of a period 'Internship' for Engineering Graduates, is highly recommended, as in some of the other professions such as Medicine, Law and Accountancy.

Furthermore, a period more than four years of practical experience after graduation, is also recommended in view of Continous Professional Development (CPD) in view of the Professional Development (PR) examination or Charter. 
Despite a Technical College coming into existence in 1890, very little effort has been made to broad-base and diversify the system of tertiary education, with a view to expand access, resulting in the creation of unemployable graduates, a major burden on the state. Our intellectual community and the policy makers, including the public bureaucracy have miserably failed to diversify the system, with more emphasis on technical and engineering education. We lacked qualified middle-level technical personnel, at a time the industry required them most.

The products of the engineering universities should be capable of confronting the daunting challenges in the relevant industries and solve them. They should be competent enough to venture into new research and development projects and develop new products, technologies and services.

In the immediate and short-term, they should gather the know-how and the ability to adopt technology to the appropriate local conditions and practices.

In the long-term, should establish their own indigenous Science and Technology capabilities to be internationally competitive.

Nevertheless, the lack of Research and Development capabilities, weak industries, the lack of proper institutional mechanisms and the lack of favourable Government policies among others, will be major constraints and issues that would have to be faced in the process.

The Regulatory framework and the parameters, within which the engineering fraternity is expected to operate, would also be important. They would be expected to comply with the Construction Industry Act, the Engineering Act of Sri Lanka and the structure and practice of the IESL, the EMF and the Washington Accord.

The Construction Industry Development Act will provide for the overall development of the Construction Industry in Sri Lanka by facilitating the regulation, formalizing and the standardization of the activities related to the Construction Industry.

It will provide for the establishment of a National Advisory Council on Construction, an authority under the name Construction Industry Development Authority - in the form of restructured ICTAD which will 
have regulatory powers and a fund for the development of the Construction Industry.

The proposed Sri Lanka Engineering Council Act is expected to prevent the practice of engineering by unauthorized persons so as to safeguard the interests of the State and the people. Engineering directly deals with structures, processes, systems and machinery that make life easy for all of us. It is therefore very important that those who are engaged in the provision and construction of these services and structures, plant and machinery are conscious of the standards that have to be maintained in order to ensure public safety. Through this Act only those who are academically qualified will be authorized to practice engineering at appropriate levels.

The Institution of Engineers, Sri Lanka recently gained international recognition by becoming a full member of the Engineers Mobility Forum (EMF) and a provisional member of the Washington Accord.

The EMF is an agreement that facilitates cross-border practice by experienced professional engineers. It creates the framework for the establishment of an international standard of competence for professional engineering so that an engineer who obtained the Professional engineer status from one country will not be required to obtain any additional qualifications if he intends migrating to another country and start practicing engineering there.

The Washington Accord also establishes a set of standard for accrediting University Degrees in Engineering. A degree accredited by one member country will have to be recognized by any of the other member countries who are signatories to the Accord. The academic qualifications of an engineer who possess a degree accredited by the IESL will be duly recognized for his academic competence in any of the member countries of the Accord.

The country also needs to establish new higher educational institutions of global excellence in order to move in the direction of a knowledgedriven economy. 